INL/EXT-17-44126

December 2017

\title{
Executive Summary to the AFC Regarding the NEAMS ATF HIP
}

K. A. Gamble

J. D. Hales

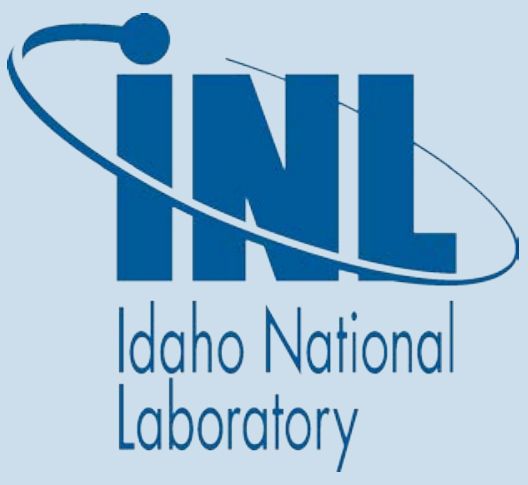




\section{NOTICE}

This information was prepared as an account of work sponsored by an agency of the U.S. Government. Neither the U.S. Government nor any agency thereof, nor any of their employees, makes any warranty, express or implied, or assumes any legal liability or responsibility for any third party's use, or the results of such use, of any information, apparatus, product, or process disclosed herein, or represents that its use by such third party would not infringe privately owned rights. The views expressed herein are not necessarily those of the U.S. Nuclear Regulatory Commission. 


\title{
Executive Summary to the AFC Regarding the NEAMS ATF HIP
}

\author{
K. A. Gamble \\ J. D. Hales
}

December 2017

Idaho National Laboratory

Fuel Modeling and Simulation Department

Idaho Falls, Idaho 83415

\author{
Prepared for the \\ U.S. Department of Energy \\ Office of Nuclear Energy \\ Under U.S. Department of Energy-Idaho Operations Office \\ Contract DE-AC07-05ID14517
}


Following the events that occurred at the Fukushima Daiichi nuclear power plant in March 2011, research into fuel and cladding materials with enhanced accident tolerance was accelerated by many nations, corporations, and research institutions. In the United States, this acceleration has occurred through the Department of Energy's (DOE) Office of Nuclear Energy's Fuel Cycle Research and Development (FCRD) Advanced Fuels Campaign (AFC). An early product of this effort was the publication entitled "Light Water Reactor Accident Tolerant Fuel Performance Metrics” [1], which outlines the metrics to be used to help guide the selection of materials that provide enhanced accident tolerance. The report defines these materials as those that provide increased response time in the event of an accident (e.g., Loss of Coolant Accident) while providing similar or improved performance as the standard $\mathrm{UO}_{2} /$ Zircaloy fuel rods during normal operation. The original goal of the AFC program was to insert candidate fuel and cladding materials into a commercial reactor as part of a lead test rod or assembly by 2022. Industry enthusiasm has moved this date ahead.

To help address this aggressive development schedule where a comprehensive set of experiments cannot be completed in time to provide material characterization data of candidate materials, the DOE through its Nuclear Energy Advanced Modeling and Simulation (NEAMS) program introduced so called High Impact Problems (HIPs). A HIP is intended to make significant advancements in a particular area of nuclear research in a short period of time (3 years or less). The first HIP selected by NEAMS was in the area of Accident Tolerant Fuels (ATF). The purpose of this executive summary is to compile the ATF materials investigated, computational models developed, and key findings of using the models in the engineering scale fuel code developed partially by NEAMS called BISON [2].

In collaboration with the AFC, two candidate materials were chosen at the onset of the HIP in FY 2015: uranium silicide ( $\mathrm{U}_{3} \mathrm{Si}_{2}$ ) fuel and iron-chromium-aluminum (FeCrAl) claddings. These materials were chosen because at the time they were foreseen to have a reasonable likelihood of being placed in a commercial reactor in the short term.

$\mathrm{U}_{3} \mathrm{Si}_{2}$ is being explored as a replacement to $\mathrm{UO}_{2}$ in fuel rods due to its higher thermal conductivity and uranium density [3] when compared to $\mathrm{UO}_{2}$. A higher thermal conductivity is expected to result in lower fuel centerline temperatures and temperature gradients within the fuel pellet. A higher uranium density is economically attractive since it may enable operation to higher burnups and longer cycle lengths. In addition to the advantages described, there exist potential disadvantages and unknowns in regards to $\mathrm{U}_{3} \mathrm{Si}_{2}$ performance under light water reactor conditions. Early work by Harp et al. [4] has indicated that $\mathrm{U}_{3} \mathrm{Si}_{2}$ is more susceptible to chemical reaction than $\mathrm{UO}_{2}$. Furthermore, $\mathrm{U}_{3} \mathrm{Si}_{2}$ appears to oxidize more than $\mathrm{UO}_{2}[5,6]$. The gaseous swelling and fission gas release behavior of $\mathrm{U}_{3} \mathrm{Si}_{2}$ is mostly unknown. At the onset of the HIP, the only experimental data available, based upon research reactor dispersion fuels [7], indicated significant fuel swelling that was attributed to a change in microstructure from crystalline to amorphous.

FeCrAl is being explored as a replacement to zirconium-based claddings due to its slower oxidation kinetics [8, 9, 10,11], increased strength [9] and higher yield stress [8]. Slower oxidation kinetics will result in less hydrogen production in accident conditions, hydrogen production being a significant contributing factor to the explosions experienced at the Fukushima 
Daiichi plant. Increased strength and yield stress result in less plastic deformation of the cladding during accident conditions resulting in a more coolable geometry compared to zirconium based alloys. Unfortunately, the thermal neutron absorption cross-section is about 10 times that of Zircaloy, which necessitates thinner cladding. Current estimates indicate that this requirement will impose a fuel cost increase of $15-35 \%[8,9]$. In addition, tritium release to the coolant when using FeCrAl as a cladding material is expected to be higher due to a permeability of hydrogen approximately 100 times higher than Zircaloy [12]. Unknowns include irradiation embrittlement [9] and its effect on burst openings.

To confirm some of the advantages and investigate some of the disadvantages and unknowns, material and behavior models were added to the BISON fuel performance code using a combination of multiscale multiphysics and empirical approaches to support the AFC program. In addition to fundamental thermal and mechanical models, three key models were developed and incorporated into BISON for fuel performance analyses. These are a rate theory gaseous swelling and thermal conductivity degradation model for $\mathrm{U}_{3} \mathrm{Si}_{2}$, a coupled gaseous swelling and fission gas release model for $\mathrm{U}_{3} \mathrm{Si}_{2}$, and an empirical burst (failure) model for FeCrAl.

Numerous rate theory simulations that mechanistically treat the evolution of voids and interstitials in the fuel were run to generate the dataset used to create a gaseous swelling and thermal conductivity degradation model for inclusion into BISON [13]. The model depends upon three factors: temperature, temperature gradient, and fission density, with ranges of

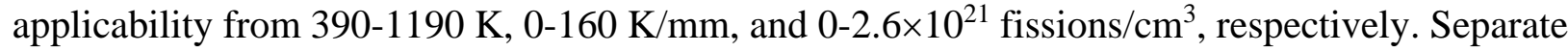
effect and integral rod simulations indicate that at light water reactor temperatures gaseous swelling strains are significant and induce large stresses within the cladding. Thermal conductivity degradation, on the other hand, appears to be negligible as centerline temperatures during normal operation increase by less than $10 \mathrm{~K}$.

Using parameters obtained by density functional theory calculations, a coupled fission gas release and gaseous swelling model was developed to predict fission gas behavior of $\mathrm{U}_{3} \mathrm{Si}_{2}$ under light water reactor conditions. This model, like the rate theory model, predicts significant gaseous swelling particularly at high temperatures. In addition, significant gas release is expected at temperatures above $1000 \mathrm{~K}$ which is expected to result in high rod internal pressures. Since $\mathrm{U}_{3} \mathrm{Si}_{2}$ operates at a much lower temperature than $\mathrm{UO}_{2}$ for the same operating power, the total amount of fission gas release under normal operation is expected to be similar.

One way to assess whether FeCrAl does in fact provide improved accident tolerance based upon the definition in the AFC report referenced above is to assess when FeCrAl claddings would burst compared to Zircaloy claddings under identical operating conditions. To do this, an empirical burst model was developed [14] by fitting the experimental data of Massey et al. [15] and applying it to separate effect experiments conducted on Zircaloy-4 tubes for which the operating conditions were known. The key observations of the Massey et al. experiments and burst model studies indicate that 1) the rupture opening in burst rods is larger in FeCrAl tubes compared to Zircaloy-4 tubes, 2) the time to burst and pressure at burst are similar between FeCrAl tubes and Zircaloy-4 tubes when taking into account the reduction in thickness of $\mathrm{FeCrAl}$ to overcome the neutronic penalty, and 3) due to its higher strength and lower creep 
rates, the strain at burst is lower in FeCrAl tubes. This final point indicates that FeCrAl assembly coolability would be higher than Zircaloy-4 assemblies.

While new models have been developed and comparative analyses between the ATF concepts and traditional materials have been completed, much still needs to be done to fully understand the behavior of $\mathrm{U}_{3} \mathrm{Si}_{2}$ and $\mathrm{FeCrAl}$ under light water reactor conditions. In particular, the experimental data currently being obtained by the AFC program is required to validate the models developed as part of the HIP. While some of the models have been developed using a mechanistic approach to help predict what would be expected to occur, actual experimental data is required to confirm the predictions. Specifics of the experimental measurements that would be beneficial in model development and validation include the following:

For $\mathrm{U}_{3} \mathrm{Si}_{2}$ :

- Microstructure

o Composition

o Phase morphology

o Radiation induced defects

o Grain size (size distribution)

o Grain boundary character

o Self and Xe diffusivities

o Electronic structure and magnetic properties

- Overall Properties

o Thermal conductivity

o Phonon and electronic

o Elastic moduli

o Creep behavior

- Swelling

o Total swelling

o Intragranular bubble size

o Intragranular bubble density

o Intergranular bubble size

o Intergranular bubble density

o Fractional grain boundary bubble coverage

o Dihedral angles of intergranular bubbles

o Gas pressure inside bubbles

- Fission Gas Release

For FeCrAl:

- Microstructure

o Composition

o Phase morphology (size and density of Cr-rich precipitates)

o Radiation induced defects

- Overall Properties

o Elastic moduli

o Yield strength

o Corrosion: oxide morphology and growth rate 
o Creep behavior as a function of time, particularly irradiation creep

0 Irradiation hardening and embrittlement

o Additional burst data (time, pressure, and cladding profilometry at burst)

Ideally, the above data would be available at a variety of temperatures and burnups.

In conclusion, the NEAMS ATF HIP has been successful in developing new models and performing qualitative comparisons between ATF concepts and traditional fuel rod materials to assess whether $\mathrm{U}_{3} \mathrm{Si}_{2}$ and $\mathrm{FeCrAl}$ provide enhanced accident tolerance. The main findings of the engineering scale analyses as part of the ATF HIP include:

- Gaseous swelling is a potential concern in $\mathrm{U}_{3} \mathrm{Si}_{2}$ particularly at high temperatures and burnups.

- The degradation of the thermal conductivity of $\mathrm{U}_{3} \mathrm{Si}_{2}$ due to interstitials, defects, and gas bubbles is negligible. With a $20 \%$ decrease in thermal conductivity centerline temperatures increase less than $10 \mathrm{~K}$.

- The low melting temperature of $\mathrm{U}_{3} \mathrm{Si}_{2}$ is of potential concern during Reactivity Insertion Accidents.

- The improved oxidation kinetics of FeCrAl alloys demonstrate significantly smaller oxide thicknesses and less hydrogen production.

- Higher strength and lower creep rates result in lower strains in FeCrAl resulting in improved assembly coolability compared to Zircaloy-4.

- Upon failure the rupture size in FeCrAl tubes is larger than for Zircaloy-4 tubes.

- The time to failure (rupture) under LOCA conditions between FeCrAl and Zircaloy-4 are similar.

This executive summary only touches on the work done as part of the ATF HIP. Significant contributions from Idaho National Laboratory, Los Alamos National Laboratory, Argonne National Laboratory, and the University of Tennessee-Knoxville have not been reported here. For further details into the model development, simulations completed, and conclusions obtained as part of the NEAMS ATF HIP, please see the full end-of-HIP report entitled "Nuclear Energy Advanced Modeling and Simulation (NEAMS) Accident Tolerant Fuels High Impact Problem: Engineering Scale Models and Analysis” [16]. 


\section{References}

[1] S. Bragg-Sitton, B. Merrill, M. Teague, L. Ott, K. Rob, M. Farmer, M. Billone, R. Montgomery, C. Stanek, M. Todosow, and N. Brown, “Advanced Fuels Campaign Light Water Reactor Accident Tolerant Fuel Performance Metrics,” Technical Report INL/EXT13-29957, Idaho National Laboratory 2014.

[2] R. L. Williamson, J. D. Hales, S. R. Novascone, M. R. Tonks, D. R. Gaston, C. J. Permann, D. Andrs, and R. C. Martineau, "Multidimensional Multiphysics simulation of nuclear fuel behavior,” Journal of Nuclear Materials, 423, 149-163, 2012.

[3] J. T. White, A. T. Nelson, J. T. Dunwoody, D. J. Safarik, and K. J. McClellan, “Corrigendum to Thermophysical Properties of $\mathrm{U}_{3} \mathrm{Si}_{2}$ to $1777 \mathrm{~K}$," Journal of Nuclear Materials, 484, 386387, 2017.

[4] J. M. Harp, L. He, R. E. Hogan, and A. R. Wagner, "Corrosion and interdiffusion studies of U3Si2,” In Proceedings of TopFuel, Boise, ID, 2016.

[5] E. S. Wood, J. T. White, D. D. Byler, and A. T. Nelson, "The synthesis and air oxidation behavior of U-Si-Al and U-Si-B compositions,” In Proceedings of TopFuel, Boise, ID, 2016.

[6] J. T. White, E. S. Wood, J. T. Dunwoody, and A. T. Nelson, "State of knowledge and challenges of U-Si compounds for use in light water reactor accident tolerant fuel designs," In Proceedings of TopFuel, Boise, ID, 2016.

[7] M. R. Finlay, G. L. Hofman, and J. L. Snelgrove, "Irradiation behaviour of uranium silicide compounds,” Journal of Nuclear Materials, 325, 118-128, 2004.

[8] R. E. Stachowski, R. B. Rebak, W. P. Gassmann, and J. Williams, "Progress of GE development of accident tolerant fuel FeCrAl cladding,” In Proceedings of TopFuel, Boise, ID, 2016.

[9] K. A. Terrani, S. J. Zinkle and L. L. Snead, “Advanced oxidation-resistant iron-based alloys for LWR fuel cladding,” Journal of Nuclear Materials, 448, 420-435, 2014.

[10] B. A. Pint, K. A. Terrani, Y. Yamamoto, and L. L. Snead, "Material Selection for Accident Tolerant Fuel Cladding,” Metallurgical and Materials Transactions E, 2E, 190-196, 2015.

[11] K. A. Terrani, B. A. Pint, K. A. Unocic, Y. Yang, C. M. Silva, H. M. Meyer III, and R. B. Rebak, "Uniform corrosion of FeCrAl alloys in LWR coolant environments," Journal of Nuclear Materials, 479, 36-47, 2016.

[12] X. Hu, K. A. Terrani, B. D. Wirth, and L. L. Snead, "Hydrogen permeation in FeCrAl alloys for LWR cladding application,” Journal of Nuclear Materials, 461, 420-435, 2014.

[13] Y. Miao, K. A. Gamble, D. Andersson, B. Ye, Z. Mei, G. Hofman, and A. M. Yacout, "Gaseous swelling of $\mathrm{U}_{3} \mathrm{Si}_{2}$ during steady state LWR operation: A rate theory investigation,” Nuclear Engineering and Design, 322, 336-344, 2017.

[14] K. A. Gamble, T. Barani, D. Pizzocri, J. D. Hales, K. A. Terrani, and G. Pastore, “An investigation of FeCrAl cladding behavior under normal operating and loss of coolant conditions,” Journal of Nuclear Materials, 491, 55-66, 2017.

[15] C. P. Massey, K. A. Terrani, S. N. Dryepondt, and B. A. Pint, "Cladding burst behavior of Fe-based alloys under LOCA,” Journal of Nuclear Materials, 461, 420-435, 2014.

[16] K. A. Gamble, J. D. Hales, D. M. Perez, and G. Pastore, "Nuclear Energy Advanced Modeling and Simulation (NEAMS) Accident Tolerant Fuels High Impact Problem: Engineering Scale Models and Analysis,” Technical Report INL/EXT-17-43388, Idaho National Laboratory 2017. 